\title{
La celda Avesta: un método para evitar problemas de corrosión por resquicios en los ensayos electroquímicos de corrosión por picaduras $^{(\bullet)}$
}

\author{
C. Fosca ${ }^{(*)}$, C. Merino ${ }^{(* *)}$ y E. Otero ${ }^{(* *)}$ \\ Resumen Uno de los grandes problemas que suelen presentarse en los ensayos electroquímicos ideados para \\ evaluar la resistencia a la corrosión por picaduras de materiales como los aceros inoxidables es la \\ presencia simultánea de corrosión por resquicios, que suele dificultar e impedir muchas veces la \\ interpretación de los resultados electroquímicos. Este mecanismo de corrosión localizada se produce \\ como consecuencia de la presencia de resquicios en el ensamble de la muestra con la celda electro- \\ química de ensayo. Se han ideado numerosas formas de evitar este inconveniente, pero ninguna ha \\ resultado completamente satisfactoria. En el presente estudio se evalúa uno de los más nuevos e \\ ingeniosos procedimientos para eliminar el riesgo de corrosión por resquicios en los ensayos de \\ corrosión por picaduras: la celda Avesta. Se efectuaron ensayos de polarización anódica electroquí- \\ mica en un acero inoxidable de alta aleación. Los resultados obtenidos con este método son compara- \\ tivamente más fiables y representativos del comportamiento electroquímico del material que los \\ métodos convencionales de preparación de muestras para evitar la presencia de resquicios.
}

Palabras clave: Corrosión por picaduras. Aceros inoxidables. Ensayos de corrosión eletroquímicos. Potencial crítico de picaduras.

\section{The Avesta cell: A method to avoid crevice corrosion during the electrochemical pitting corrosion tests}

\begin{abstract}
A very common problem, that occurs during the electrochemical pitting corrosion tests of CRAs (corrosion resistant alloys) as stainless steels, is the simultaneous occurrence of crevice corrosion that difficults the evaluation of the electrochemical behaviour in presence of pitting corrosion mechanism only. Crevice corrosion appears as a consequence of the formation of crevices during the mountage of the specimen in the electrochemical cell. Several forms have been developed to avoid the presence of crevice during the electrochemical pitting corrosion test, but without satisfactory results. In the present study a relatively new and innovative method to eliminate the risk of crevice corrosion in the electrochemical tests is evaluated the Avesta cell. Anodic polarization electrochemical tests were carried out in a high alloy stainless steel in $3 \% \mathrm{NaCl}$ solution. The experimental results obtained using the Avesta cell were more fiable, reproducible and representative of the electrochemical behaviour of the material that those obtained using other methods of samples preparation to avoid the crevice formation.
\end{abstract}

Keywords: Pitting corrosion. Stainless steels. Electrochemical corrosion tests. Critical pitting potential.

(•) Trabajo recibido el día 21 de julio de 1995.

(*) Instituto de Corrosión y Protección. Dpto. de Ingeniería. Pontificia Universidad Católica del Perú. Avda. Universitaria Cuadra 18. San Miguel. Lima 32 (Perú).

(**) Dpto. de Ciencia de los Materiales e Ingeniería Metalúrgica. Facultad de Ciencias Químicas. Universidad Complutense de Madrid. 28040-Madrid (España).

\section{INTRODUCCIÓN}

Los ensayos electroquímicos permiten la evaluación rápida del comportamiento frente a la corrosión por picaduras de los aceros inoxidables. La mayoría de estos ensayos contempla la evaluación de dos parámetros: el potencial crítico de picaduras, $\left(E_{\mathrm{cp}}\right)$, y el potencial crítico de repasivación de picaduras o potencial de protección, $\left(E_{\mathrm{rp}}\right)$. 
En la figura 1 se muestran los cambios que se producen en la curva de polarización electroquímica cuando el acero inoxidable se encuentra en contacto con un medio acuoso que contiene cloruros. Cuando se encuentra en un medio acuoso neutro, sin la presencia de cloruros, la curva de polarización anódica se puede representar como la curva 1 (Fig. 1). Existe una zona de pasivación muy bien definida, donde el material se encuentra protegido. A partir de un potencial denominado de transpasivación $\left(E_{\mathrm{tr}}\right)$ la corriente anódica crece significativamente debido a la descomposición del agua:

$$
2 \mathrm{H}_{2} \mathrm{O} \rightarrow \mathrm{O}_{2}+4 \mathrm{H}^{+}+4 \mathrm{e}^{-}
$$

y a la reacción de oxidación

$$
\mathrm{Cr}^{3+} \rightarrow \mathrm{Cr}^{6+}+3 \mathrm{e}^{-}
$$

que produce la disolución del material.

El potencial $E_{\mathrm{tr}}$ alcanza valores bastante nobles (> $1.000 \mathrm{mV}$ ECS), resultando muy difícil que en la práctica el acero inoxidable alcance estas condiciones (salvo en el caso de ambientes extremadamente oxidantes) y, por tanto, su condición normal suele ser el estado pasivo.

Cuando el medio contiene cloruros, la estabilidad de la capa pasiva se ve afectada y la ruptura localizada de la película de óxido protector da lugar a la nucleación de picaduras por encima del denominado $E_{\mathrm{cp}}$, como se aprecia en la curva 2 de la figura 1. Por debajo de este potencial no hay posibilidad de nucleación de las picaduras. Sin embargo, una picadura ya formada puede continuar su crecimiento y propagación a través del material incluso

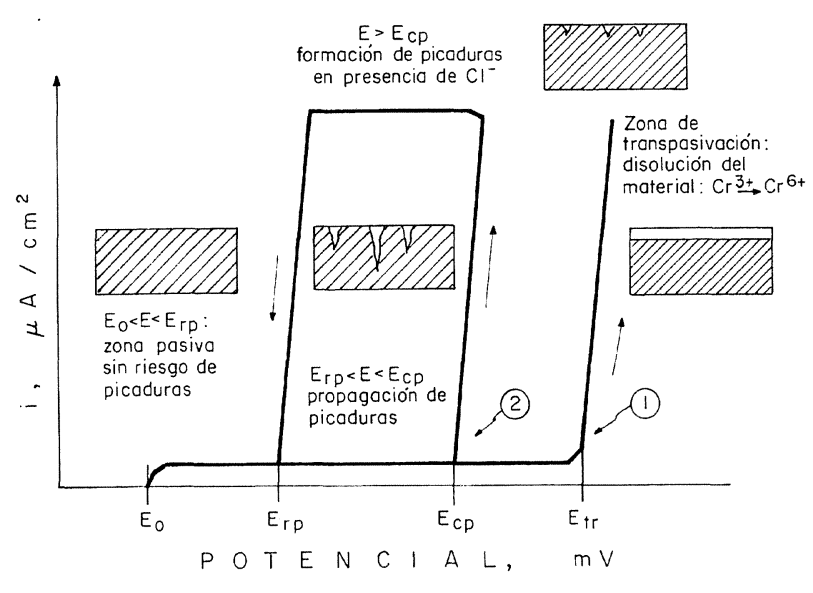

FIG. 1.- Representación de curvas electroquímicas de aceros inoxidables en presencia o no de corrosión por picaduras.

FIG. 1.- Schematic representation of the electrochemical polarization curves of stainless steels in presence and absence of pitting corrosion. a potenciales menores que $E_{\mathrm{cp}}$. Las condiciones de repasivación del fondo de la picadura y, por tanto, la detención del proceso de crecimiento de una picadura ya nucleada, se presentan a potenciales por debajo del $E_{\mathrm{rp}}$. El criterio electroquímico de protección contra la corrosión por picaduras de un acero inoxidable, sería procurar que su potencial en el medio agresivo nunca sobrepase el valor de $E_{\mathrm{rp}}$. Por ello, muchos autores (1) suelen denominar a este valor potencial de protección. Sin embargo, este potencial de protección no es una propiedad del material, sino que, por el contrario, depende en gran medida del procedimiento experimental empleado para su determinación (2).

La determinación de estos potenciales se puede realizar mediante numerosas técnicas electroquímicas, de carácter estático, cuasi estático o dinámico, bajo control de potencial (ensayos potenciostáticos y potenciodinámicos) o de corriente (ensayos galvanostáticos o galvanocinéticos). Autores como Oldfield (1), Smialowska et al. (3) han revisado muy documentadamente las ventajas y desventajas de cada uno de estos procedimientos. Dichos autores concluyen que los valores de $E_{\mathrm{cp}}$ y $E_{\mathrm{rp}}$, determinados por las técnicas potenciodinámicas, dependen mucho de las condiciones del ensayo y sus diferencias suelen ser siempre mayores conforme aumenta la velocidad de barrido. Asimismo, las técnicas potenciostáticas y galvanostáticas permiten una determinación mucho más real de estos potenciales, pero con el inconveniente de ser ensayos extremadamente largos.

Sin embargo, si la aplicación de estas técnicas electroquímicas está orientada a establecer criterios de análisis comparativo entre materiales y/o condiciones, entonces cualquiera de los métodos pueden ser igualmente útiles (4). El ensayo de polarización anódica potenciodinámica tiene la ventaja de ser un método rápido y reproducible, que permite, a través del estudio de la curva de polarización y de los potenciales $E_{\mathrm{rp}}$ y $E_{\mathrm{cp}}$, evaluar comparativamente el comportamiento de diferentes materiales o de diferentes condiciones microestructurales frente a determinadas condiciones agresivas.

\subsection{El resquicio: "la pesadilla" de los ensayos de corrosión por picaduras}

Sin embargo, sea cual fuere la técnica electroquímica empleada, siempre ha existido una dificultad práctica en el momento de realizar los ensayos de corrosión por picaduras. Este verdadero "dolor de cabeza" para todos los investigadores que han evaluado experimentalmente la resistencia a la corrosión por picaduras lo constituye la presencia inevitable de resquicios en el montaje de la muestra y la consiguiente presencia de este otro mecanismo 
de corrosión localizada durante la ejecución del ensayo.

La presencia de resquicios en las muestras es consecuencia del procedimiento empleado para mantenerlas sumergidas en la solución y permitir a su vez la conexión eléctrica entre estas y el potenciostato. La figura 2 muestra dos de los ejemplos más comunes de formación de resquicios, debidos al montaje de las probetas de ensayo (porta-electrodo) en la celda electroquímica. Otros tipos de montajes usados con frecuencia consisten en recubrir parcialmente con una laca o cinta adhesiva la superficie de la muestra o sumergirla parcialmente en la solución. Lo cierto es que ninguno de los montajes resulta adecuado para evitar el efecto de resquicio; por el contrario, estos son precisamente los causantes de una mayor susceptibilidad a la corrosión por resquicios de las muestras.

La corrosión por resquicios en los aceros inoxidables es otro tipo de corrosión localizada que se produce en regiones del material (resquicios) con acceso restringido del oxígeno disuelto, creando una macropila de aeración diferencial. En estas condiciones, la composición de la solución dentro del resquicio va cambiando gradualmente en relación con la solución de la superficie libre del material, dando lugar a un incremento de la concentración de iones agresivos $\left(\mathrm{Cl}^{-}\right)$y de protones $\mathrm{H}^{+}$que reducen su $\mathrm{pH}$ (5). Finalmente, se alcanza en el resquicio un ambiente lo suficientemente agresivo para que se produzca la ruptura irreversible de la capa pasiva protectora dando inicio a la propagación de la corrosión localizada.

Muchos autores ( 2 y 6 ) han concluido que los mecanismos de propagación de la corrosión por picaduras y por resquicios son prácticamente los mismos. Sin embargo, los mecanismos de iniciación de ambos procesos de corrosión son diferentes, estando cinéticamente más favorecida la corrosión por resquicios. Debido a ello, cuando se emplean técnicas electroquímicas para determinar el $E_{\mathrm{cp}}$, se puede incurrir en graves errores de estimación de
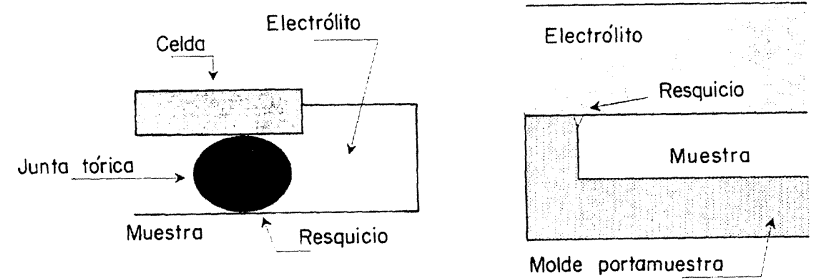

Fig. 2.- Ejemplos de formas geométricas que propician resquicios durante los ensayos electroquímicos de corrosión por picaduras.

FIG. 2.- Examples of typical geometric configuration in mountages of the samples in the electrochemical cell that promote crevice corrosion. este valor como consecuencia de la aparición previa de corrosión por resquicios a potenciales más negativos que el valor $E_{\mathrm{cp}}$.

Para evitar o reducir la presencia de corrosión por resquicios en los ensayos de corrosión por picaduras, se han probado diversos métodos de tratamiento superficial (7 y 8) y diseñado numerosos portaelectrodos (9-13) que permitan al menos reducir la incidencia de la corrosión por resquicios durante los ensayos electroquímicos. La figura 3 muestra esquemáticamente algunos portamuestras diseñados para eliminar o reducir el riesgo de resquicios.

Algunos de estos dispositivos incluso han sido adoptados por normas internacionales, como la ASTM G5 (14)(Fig. 3a) y la ASTM G-61 (15)(Fig. $3 b)$. Sin embargo, la presencia cada vez mayor de nuevos diseños y nuevos métodos de sujeción de las muestras durante los ensayos son un claro indicio de que ninguna de las técnicas anteriores logra evitar la presencia indeseable de resquicios.

Soria et al. (16) estudiaron con profundidad el problema de los resquicios provenientes del montaje de las muestras. Estudiaron más de 20 técnicas de preparación del electrodo de trabajo, empleando para ello un acero inoxidable del tipo AISI 304. La figura 3c) muestra el esquema del portaelectrodo empleado en este estudio. Los mejores resultados se consiguieron mediante la combinación de un montaje en resina epóxica y la aplicación de un tratamiento previo de pasivación en ácido nítrico en los bordes de la superficie expuesta del acero.

La resistencia a la corrosión por resquicios, al igual que la resistencia a la corrosión por picaduras de los aceros inoxidables, depende muy acusadamente de la composición química de la aleación. Un aumento del contenido de cromo, molibdeno y nitrógeno en los aceros inoxidables incrementa su resistencia a ambos mecanismos de corrosión localizada. Sin embargo, es importante observar lo siguiente: en aceros inoxidables de menor aleación, el efecto de la presencia de un resquicio sobre los valores del $E_{\mathrm{cp}}$ y/o sobre la temperatura crítica de picaduras puede ser menos significativo que el observado en aceros inoxidables de mayor aleación. En los aceros inoxidables más resistentes se requieren condiciones del medio más agresivas (mayores temperaturas, mayores contenidos de $\mathrm{Cl}^{-}$y menores valores de $\mathrm{pH}$ ) para producir corrosión por picaduras. En estas condiciones, el $E_{\mathrm{cp}}$ se puede diferenciar notablemente al potencial crítico de resquicios, incrementando con ello las dificultades asociadas a la interpretación de los resultados electroquímicos en presencia de resquicios accidentales. Por ello, resulta más sencillo resolver problemas de resquicios en el montaje de las muestras para ensayos electroquímicos si se ensaya un acero inoxidable del tipo $18 \mathrm{Cr}-8 \mathrm{Ni}$ que si se ensaya un acero de los tipos $25 \mathrm{Cr}-7 \mathrm{Ni}-3$ Mo ó $20 \mathrm{Cr}-18 \mathrm{Ni}-6 \mathrm{Mo}$. 


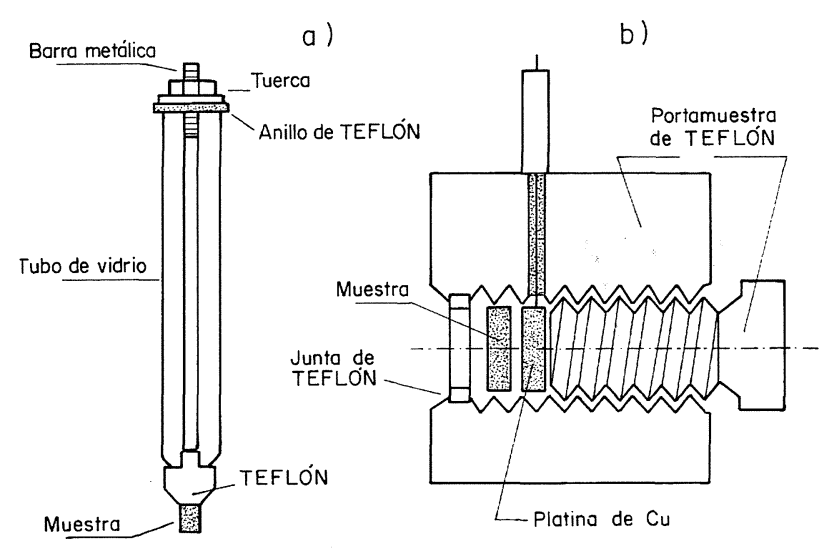

c)

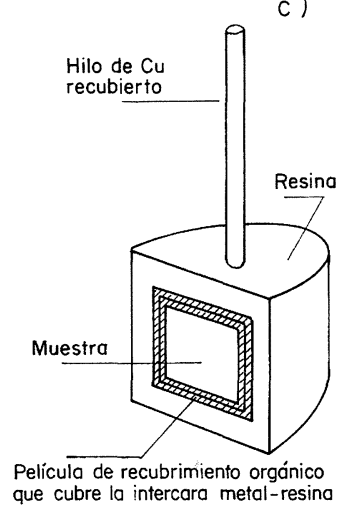

FIG. 3.- Representación esquemática de diferentes portaelectrodos empleados para evitar los resquicios en los ensayos electroquímicos de corrosión.

FIG. 3.- Schematic representation of different specimen holders designed to avoid crevice corrosion during corrosion electrochemical tests.

\subsection{La celda Avesta: un enfoque diferente del problema}

La mayoría de las soluciones propuestas hasta el momento para eliminar el riesgo de corrosión por resquicios en los ensayos electroquímicos de corrosión por picaduras no han conseguido resolver este problema. Qvarfort publicó en 1988 (17), por primera vez, el desarrollo de un nuevo diseño de celda electroquímica que eliminaba todo riesgo de corrosión por resquicio como consecuencia del montaje de la muestra en la celda, permitiendo la determinación precisa del $E_{\mathrm{cp}} \mathrm{y}$ de la temperatura crítica de picadura (CPT).

El principio en que se basa esta nueva celda es bastante singular. Mientras que los métodos anteriores procuraban eliminar o reducir al máximo el riesgo de la existencia de resquicios, en este nuevo diseño se aceptaba e incluso se procuraba localizar bien el resquicio en el montaje de la celda. El principio por el que se regían todos los otros métodos era muy simple: "sin resquicios no habrá corrosión por resquicios". La filosofía del diseño de esta nueva celda, por cierto más complicada, era como elegir el camino más largo y sinuoso para llegar más rápidamente al destino propuesto.

El resquicio es un factor geométrico que, junto con otros tantos factores, como la composición química de la aleación, la composición del electrólito, la temperatura, la agitación del medio, la concentración de oxígeno disuelto en la solución, condicionan el comportamiento de un material frente a la corrosión por resquicios. En los aceros inoxidables, este tipo de corrosión se presenta como consecuencia de la formación de una celda de airación diferencial y un proceso de acidificación local del electrólito confinado en el resquicio, que despasiva la superficie del acero provocando su disolución (18). La presencia del resquicio en la superficie del material es un requisito para alcanzar fácilmente estas condiciones, pero la causa directa de la corrosión localizada no es el resquicio en sí, sino la formación de un ambiente agresivo dentro del mismo que provoque la disolución continua del material.

.Esta es, en resumidas cuentas, la filosofía de la celda Avesta. La eficacia del método no radica en eliminar el resquicio, sino en impedir la concentración de iones agresivos y el proceso de acidificación dentro del mismo. Para ello, la solución agresiva dentro del resquicio es reemplazada continuamente por agua destilada que se suministra desde el exterior hacia el interior de la celda.

La figura 4 muestra esquemáticamente el principio de esta celda. Dentro de una cámara circular limitada por dos juntas tóricas concéntricas se bombea un flujo de agua destilada. La junta exterior, en contacto con la muestra y el portamuestra, sella herméticamente la cámara. La junta tórica interior no se encuentra en contacto directo con la muestra, sino a través de un anillo hecho de papel de filtro poroso, que permite que el agua destilada, confinada en la cámara, fluya lentamente hacia el interior de la celda. La solución agresiva localizada en el

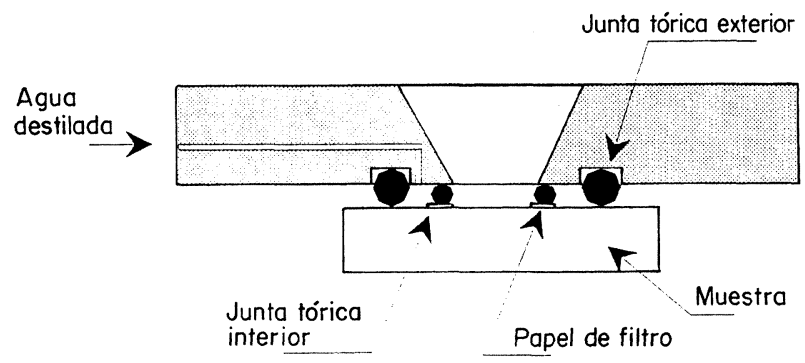

FIG. 4.- Esquema del dispositivo empleado en la celda Avesta para eliminar la solución agresiva del interior del resquicio.

FIG. 4.- Scheme of the device employed in the Avesta cell in order to avoid the formation of an aggressive solution into the crevice. 
resquicio, que forma en este caso la junta tórica interior, se diluye continuamente por el flujo de agua destilada. La menor densidad del agua permite que esta fluya inmediatamente hacia arriba, a través de las paredes del portamuestras, de tal forma que sólo el resquicio y el perímetro de la superficie de ensayo está en contacto con el agua destilada.

El flujo de agua destilada necesario para eliminar el riesgo de corrosión por resquicios es bastante pequeño: $4-5 \mathrm{ml} / \mathrm{h}$ (19), lo que no produce una disolución significativa del medio agresivo. Por ejemplo, una solución de $150 \mathrm{ml}$ de $3 \% \mathrm{NaCl}$, experimentaría una disolución del $3 \%$ aproximadamente después de $1 \mathrm{~h}$ de ensayo.

\section{PROCEDIMIENTO EXPERIMENTAL}

El estudio electroquímico de la susceptibilidad a la corrosión por picaduras se llevó a cabo en un acero inoxidable dúplex del tipo $25 \% \mathrm{Cr}-7 \% \mathrm{Ni}-3$ $\%$ Mo-0,15\% N. El material se solubilizó a $1.373 \mathrm{~K}\left(1.100{ }^{\circ} \mathrm{C}\right)$ durante $1 \mathrm{~h}$ y posteriormente se enfrió en agua, vigorosamente agitada, hasta la temperatura ambiente.

Se realizaron ensayos de polarización anódica en soluciones acuosas que contenían $3 \% \mathrm{NaCl}$. Con el fin de estudiar la eficacia de la celda Avesta como procedimiento para evitar los problemas vinculados a la presencia de resquicios en los ensayos de corrosión por picaduras, se realizaron ensayos comparativos empleando un tipo de portamuestra convencional. Tomando como referencia los resultados del estudio de Soria et al. (16), se eligió el siguiente procedimiento de preparación de muestras para ser ensayadas sin emplear la celda Avesta:

- Las muestras fueron desbastadas superficialmente por vía húmeda empleando papel abrasivo hasta grado 600.

- Posteriormente, las muestras fueron sometidas a un tratamiento de pasivado por inmersión en una solución de $60 \% \mathrm{HNO}_{3}$ a $333 \mathrm{~K}\left(60{ }^{\circ} \mathrm{C}\right)$ durante $15 \mathrm{~min}$.

- Cada muestra fue embutida en caliente, empleando resina epóxica termoendurecible de baja contracción y elevada dureza, para reducir el riesgo de formación de hendiduras y relieve en la intercara metal-portamuestra.

- Adicionalmente, se aplicó una película fina de resina epóxica rodeando la intercara metal-portamuestra, para cubrir los posibles resquicios que puedan haberse formado durante el proceso de embutición. El período de curado fue de $24 \mathrm{~h}$.

- Finalmente, se procedió a desbastar la superficie de ensayo (grado 600) a fin de eliminar toda la resina que emergía de la intercara y dejar solamente aquella confinada en los resquicios.
En el caso de las muestras ensayadas empleando la celda Avesta, la preparación de las mismas se llevó a cabo de la siguiente forma:

- Todas las muestras se desbastaron por vía húmeda con papel abrasivo de carburo de silicio hasta el grado 600. Después se procedió a su limpieza e inmediata instalación en la celda electroquímica.

Para el desarrollo del presente estudio electroquímico, se construyó una celda del tipo Avesta cuyo esquema se muestra en la figura 5. El volumen de solución dentro de la celda fue de $150 \mathrm{ml}$ y la superficie de ensayo de $0,8 \mathrm{~cm}^{2}$. Con la finalidad de realizar ensayos a diferentes temperaturas, la celda electroquímica se construyó con doble pared para calentar la solución de ensayo mediante la circulación, a través del anillo exterior, de agua caliente proveniente de un baño termostático con regulación de temperatura de $\pm 1{ }^{\circ} \mathrm{C}$.

Para bombear flujos tan pequeños como $4 \mathrm{ml} / \mathrm{h}$ se emplean comúnmente microdosificadores o microbombas. En la celda electroquímica diseñada para este estudio, el agua destilada era conducida a la cámara por gravedad. La medición de flujos tan pequeños se realizó controlando el nivel de agua en una micropipeta de $5 \mathrm{ml}$, adaptada como recipiente para el agua destilada. La micropipeta se conectaba

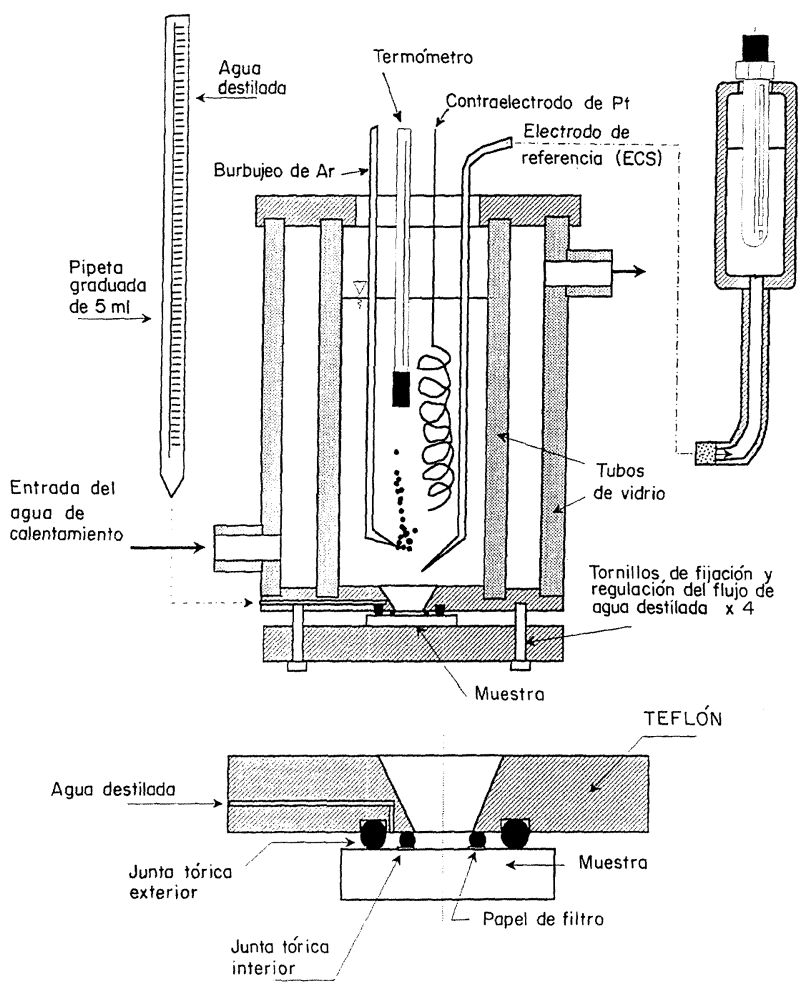

FIG. 5.- Esquema de la celda Avesta diseñada para el presente estudio.

FIG. 5. - Scheme of the Avesta cell designed for the present study. 
a la celda mediante un tubo flexible de plástico con una llave de cierre y apertura. La regulación del flujo se realizó mediante los tornillos de ajuste con los que la muestra se fijaba a la celda (Fig. 5).

El ensayo de polarización electroquímica se llevó a cabo empleando un sistema de tres electrodos: un contraelectrodo de platino, un electrodo de referencia de calomelanos saturado (ECS) y la muestra en estudio como electrodo de trabajo. El equipo empleado fue un potenciostato Amel®, mod. 551, conectado a un generador de barrido Amel ${ }^{\circledR}$ mod. 568.

Los ensayos de polarización anódica se efectuaron a una velocidad de barrido de $1 \mathrm{mV} / \mathrm{s}$, que, a pesar de ser una velocidad mayor que la recomendada por la norma ASTM G61 $(0,67 \mathrm{mV} / \mathrm{s})$, ha sido muy empleada en la bibliografía (20 y 21) para la evaluación del comportamiento frente a la corrosión localizada de materiales similares. La muestra fue mantenida al potencial de corrosión durante 15 min antes de iniciar la polarización anódica potenciodinámica. El $E_{\mathrm{cp}}$ se determinó en el momento en que la densidad de corriente alcanzaba el valor de $100 \mu \mathrm{A} / \mathrm{cm}^{2}$. Cuando la densidad de corriente alcanzaba los $400 \mu \mathrm{A} / \mathrm{cm}^{2}$, se invertía la polarización hasta alcanzar nuevamente la condición de pasivación o una densidad de corriente de 10 $\mu \mathrm{A} / \mathrm{cm}^{2}$. Después de cada ensayo, la muestra se examinaba al microscopio para verificar la presencia o no de picaduras.

\section{RESULTADOS Y ANÁLISIS}

La figura 6 muestra comparativamente los resultados de ensayos electroquímicos realizados, empleando la técnica de preparación de las muestras mediante embutido en resina, descrita anteriormente, con el procedimiento de ensayo mediante la celda tipo Avesta. En estos ensayos se empleó una solución de $\mathrm{NaCl}$ al 3,0\% $(\mathrm{pH}=6)$ en la que el material fue expuesto a $60{ }^{\circ} \mathrm{C}$.

La curva de polarización anódica del acero inoxidable dúplex DP-12 en estado solubilizado (1.373 $\mathrm{K} / 1 \mathrm{~h} /$ agua), obtenida empleando la celda tipo Avesta, muestra una región de pasivación que se extiende desde el potencial de corrosión hasta un potencial de $1.200 \mathrm{mV}$ (ECS). El incremento de la corriente que se observa a partir de este valor de potencial corresponde a la transición hacia la región de transpasividad del material. Una observación posterior de la muestra no dio evidencia alguna de ataque localizado en la zona de ensayo.

Por el contrario, las muestras preparadas según el procedimiento descrito y esquematizado en las figuras 3c) y 6 , sufrieron corrosión por resquicios a potenciales por debajo de los $700 \mathrm{mV}$ (ECS). En

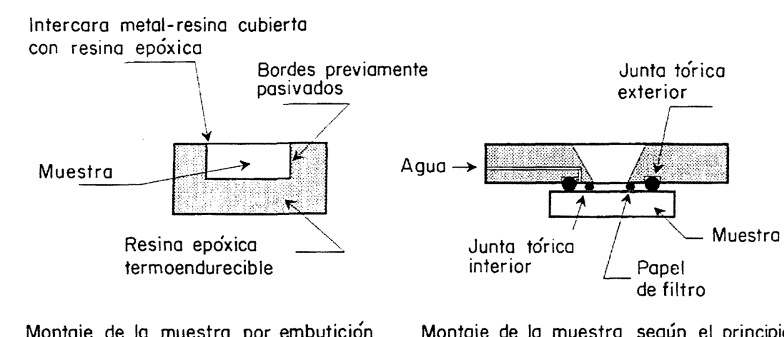

Montaje de la muestra por embutición en resina epóxica de la celda AVESTA

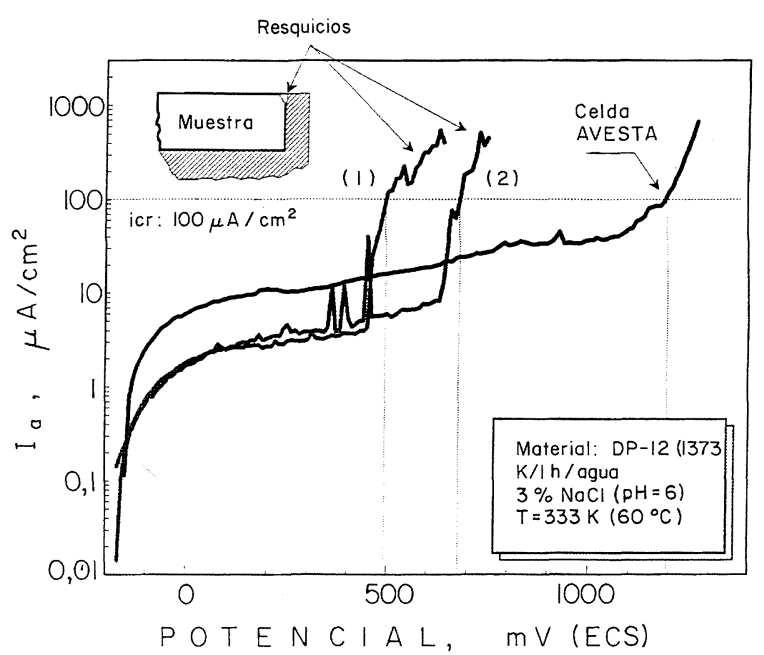

Fig. 6.- Curvas de polarización anódicas en el acero inoxidable. Se aprecia la presencia de corrosión por resquicios en las curvas (1) y (2), en comparación con la curva electroquímica obtenida empleando la celda Avesta, que alcanzó la transpasivación a potenciales más elevados.

FIG. 6.-Anodic polarization curves of the stainless steel. The curves (1) y (2) show the presence of crevice corrosion in comparison with the curve obtained employing the Avesta cell which presented only transpassivation at a higher potentials.

estas condiciones, el efecto de resquicio no permitió la evaluación adecuada del comportamiento frente a la corrosión por picaduras de este material.

En presencia de condiciones del medio más agresivas, el efecto perjudicial de los resquicios en los ensayos electroquímicos de corrosión por picaduras es mucho más significativo. La figura 7 muestra los resultados de los ensayos electroquímicos realizados en una solución de $3 \% \mathrm{NaCl}$ acidificada con $\mathrm{HCl}$ a $\mathrm{pH}=1$. A temperaturas de $293 \mathrm{~K}$ $\left(20{ }^{\circ} \mathrm{C}\right)$ y $313 \mathrm{~K}\left(40{ }^{\circ} \mathrm{C}\right)$ se advierte, a través de las curvas de polarización anódica, un comportamiento pasivo del material dentro de un amplio rango de potenciales hasta alcanzar la transpasivación. Los problemas surgen a $333 \mathrm{~K}\left(60{ }^{\circ} \mathrm{C}\right)$, donde, a pesar de todas las precauciones tomadas, la presencia de microhendiduras en la intercara metal-resina provoca la corrosión por resquicios del material. La poca reproducibilidad de los ensayos electroquímicos en presencia de micro-resquicios involuntarios se pone 

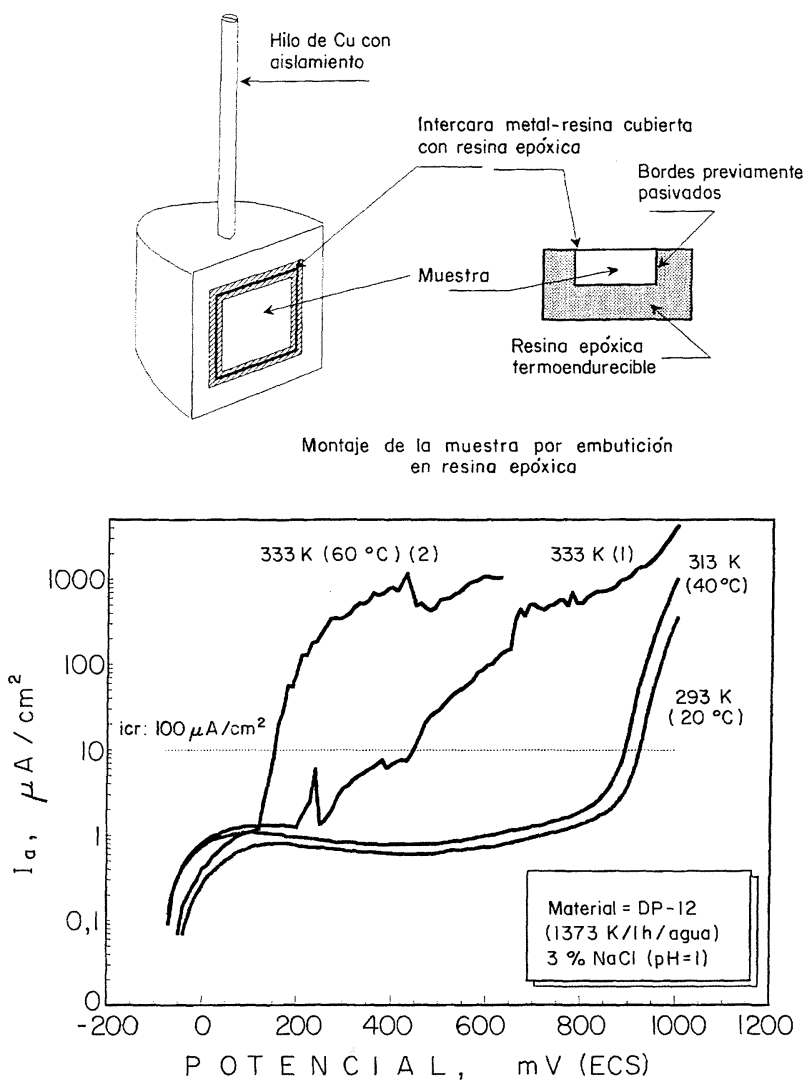

FIG. 7.- Curvas electroquímicas del acero inoxidable en un medio más agresivo $(\mathrm{pH}=1)$. La corrosión por resquicios reduce aún más el potencial crítico de resquicios. En estas condiciones, no es posible determinar el potencial crítico de picaduras, $E_{\mathrm{cp}}$.

FIG. 7.- Electrochemical curves of the stainless steel in a more aggressive solution $(\mathrm{pH}=1)$. The crevice corrosion reduced most strongly the critical crevice potential. The critical pitting potential is not possible to be valued in these conditions.

de manifiesto en las curvas (1) y (2), correspondientes a dos muestras del mismo material preparadas de acuerdo con el procedimiento descrito anteriormente. La presencia de corrosión por resquicios fue advertida en estas condiciones a potenciales inferiores a $+500 \mathrm{mV}$ (ECS), mientras que las muestras del mismo material ensayadas con la celda Avesta no presentaron ningún tipo de corrosión localizada en las mismas condiciones de ensayo.

Lo cierto es que la mayoría de los métodos de preparación de muestras referidos anteriormente no son fiables cuando las condiciones de ensayo se vuelven muy agresivas. Soria et al. realizaron los estudios a $298 \mathrm{~K}\left(25^{\circ} \mathrm{C}\right)$ en una solución neutra de $3,5 \% \mathrm{NaCl}$. Asimismo, la mayoría de los portamuestras diseñados para evitar los resquicios, a los que la literatura hace referencia, incluyendo el recomendado por la norma ASTM G-61, se ha empleado sobre todo para ensayos de corrosión a tempera- tura ambiente. Sólo el portaelectrodo de trabajo, mostrado en la figura 3d), empleado por Bogaerts et al. (13), fue diseñado específicamente para ensayos electroquímicos a temperaturas elevadas.

En comparación con estos procedimientos, el empleo de la celda Avesta ha resultado mucho más ventajoso y muy efectivo para evitar la presencia de mecanismos de corrosión por resquicios durante los ensayos electroquímicos.

\subsection{Algunas observaciones acerca de la celda Avesta}

La concepción de la celda Avesta ha permitido eliminar prácticamente el riesgo de ataque en resquicios en el montaje de las muestras; sin embargo, ha introducido en los ensayos electroquímicos otro tipo de inconvenientes:

Debido a que la muestra no se encuentra totalmente sumergida en dicha solución existe un gradiente de temperatura entre la superficie de ensayo y ésta. Este gradiente de temperatura depende en gran medida del diseño de la celda y de la agitación del medio durante el ensayo.

La figura 8 muestra los resultados de la medición de temperaturas realizada en la superficie de la muestra, en función de la temperatura de la solución. La medición de la temperatura superficial se realizó instalando un termopar, dentro de un agujero muy fino, mecanizado desde la superficie opuesta de la muestra, a una distancia menor a $1 \mathrm{~mm}$ de la superficie metálica en contacto con la solución. La solución se agitó fuertemente con un flujo de argón durante los primeros $5 \mathrm{~min}$ a fin de mejorar la transferencia de calor y luego se mantuvo un pequeño flujo de gas, durante todo el ensayo, que permitiese la homogeneización de la solución así como de la temperatura. En la misma figura se aprecia la gran influencia de la agitación sobre la temperatura de la superficie de ensayo de la muestra. Los valores de temperatura en estado estacionario se obtuvieron después de $10 \mathrm{~min}$ de haber instalado la muestra en la celda, para la solución agitada, y de 25 min para la solución sin agitar.

La mayor diferencia de temperaturas que se obtiene en la celda con la solución agitada fue de 6 $\mathrm{K}$ a $353 \mathrm{~K}\left(80{ }^{\circ} \mathrm{C}\right)$, mientras que sin agitación la temperatura superficial de la muestra presentaba diferencias, con relación a la temperatura de la solución, de $20 \mathrm{~K}$ después de $20 \mathrm{~min}$ de mantenimiento a $347 \mathrm{~K}\left(74{ }^{\circ} \mathrm{C}\right)$.

Una modificación en el diseño original de la celda Avesta permitiría reducir el problema del gradiente de temperaturas entre la muestra y la solución. Portamuestras del tipo recomendado por la norma ASTM G-61 han sido adaptados para ser 

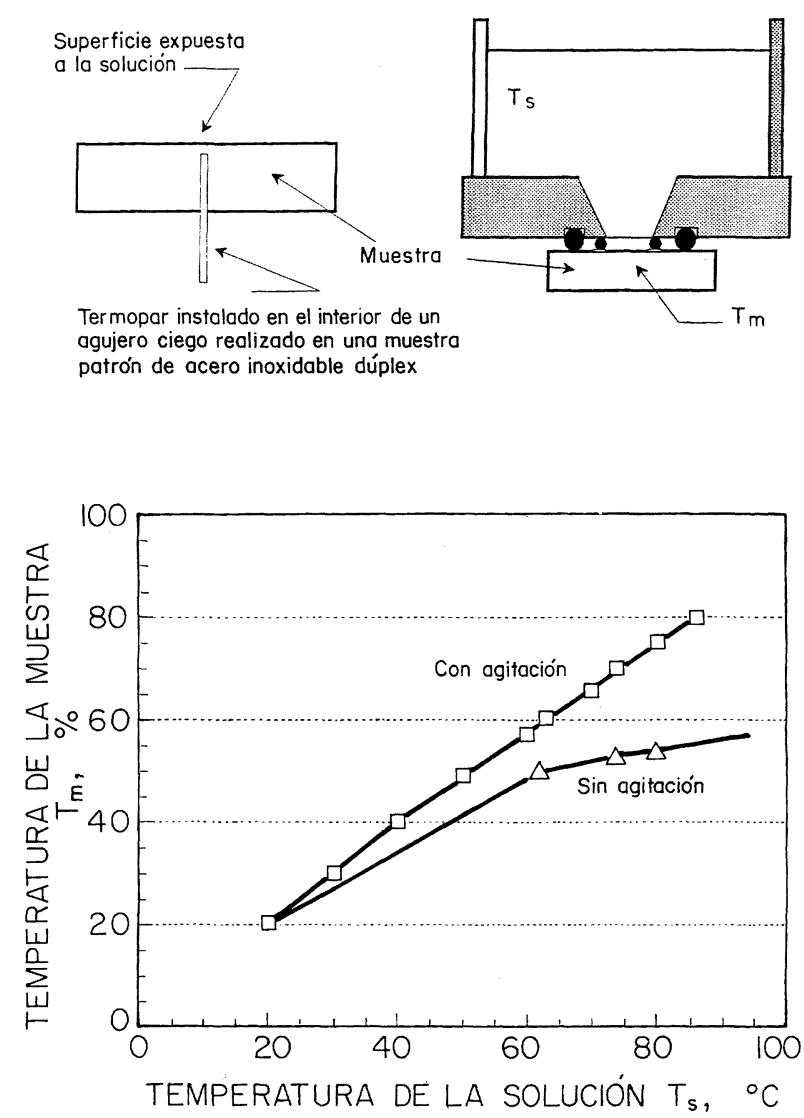

FIG. 8.- Determinación de la temperatura de la muestra, instalada en la celda tipo Avesta fabricada para el presente estudio, en función de la temperatura de la solución.

FIG. 8.- Determination of the temperature of the sample installed in the Avesta cell, designed for this study, as a function of the solution temperature.

usados según el principio de la celda Avesta. Sin embargo, su empleo a temperaturas por encima de $373 \mathrm{~K}\left(60{ }^{\circ} \mathrm{C}\right)$ puede traer complicaciones debido a que el portamuestra se dilata y el ajuste necesario entre éste y la muestra, para garantizar un flujo mínimo de agua destilada, puede variar durante el ensayo.

Otra observación importante, que se deduce de la comparación de las curvas de polarización, corresponde a las diferencias de magnitud de la densidad de corriente de pasivación. En la técnica electroquímica empleando la celda tipo Avesta se miden densidades de corriente más elevadas que en los métodos convencionales, debido a que la superficie expuesta a la solución agresiva no es la única en contacto con un electrólito. La superficie del material, en contacto con el agua destilada dentro de la cámara circular, se polariza también anódicamente durante el ensayo, incrementando la densidad de corriente neta que se mide. Cuando se produce el incremento de la corriente, como consecuencia de la aparición de corrosión por pica- duras, la componente de la corriente anódica, correspondiente a la región de material en contacto con el agua destilada, resulta despreciable. Sin embargo, en la región pasiva, su influencia puede ser significativa, como se aprecia en la figura 6 .

\section{CONCLUSIONES}

El empleo de la celda Avesta permite la determinación precisa y mas reproducible del potencial crítico de picaduras $\left(E_{\mathrm{cp}}\right)$, eliminando el riesgo de la presencia de corrosión por resquicios. Su empleo permite el estudio del comportamiento frente a la corrosión por picaduras de aleaciones de elevada resistencia a la corrosión, que requieren condiciones del medio muy agresivas y en las que la presencia de resquicios en la muestra puede ser crítica.

\section{REFERENCIAS}

(1) ، OlfiELD, J.W. Int. Mater. Rev., 32 (3), 1987: 153-170.

(2) IJSSELIn, F.P. Br. Corros. J., 15 (2), 1980: 60.

(3) SmialowsKa, S. y CZaChor, M. The analysis of electrochemical methods for the determination of characteristic potentials of pitting corrosion. Localized Corrosion NACE-3, 1974.

(4) GonZalez, J.A. Control de la Corrosión: estudio y medida por técnicas electroquímicas. CENIM (CSIC) Madrid. 1989: 142.

(5) Olfield, J.W. y Sutton, W.H. Br. Corros. J., 13 (1), 1978: 13-21.

(6) Betts, A.J. y Boulton, L.H. Br. Corros. J., 28 (4), 1993 : 279-295.

(7) Hou, W.T., Muylder, J.V. y Winand, R. Corros. Sci., 23 (12), 1983: 1.307-1.314.

(8) Kawashima, A. y Hashimoto, K. Corros. Sci., 26 (6), 1986: 467-478.

(9) Stern, M. y Makrides, A.C. Electrochem. Soc., 107 (5), 1960: 782-783.

(10) France, W.D. J. Electrochem. Soc., 114 (8), 1967: 818819.

(11) Myers, J.R., Gruenler, E.G. y Smulczenski, L.A. Corrosion NACE, 24 (10), 1986: 352-353.

(12) Greene, N.D., France, W.D. y Wilde, B.E. Corrosion NACE, 21 (9), 1965: 275-276.

(13) Bogaerts, W.F., Van Haute, A.A. y Brabers, M.J. Pitting behaviour of austenitic stainless steel at elevated temperatures. $7^{\circ}$ Congreso Internacional de Corrosión Metálica. Río de Janeiro (Brasil), Oct. 1978.

(14) ASTM G5-87. Standard Reference Test Method for Making Potentiostatic and Potentiodynamic Anodic Polarization Measurements. Annual Book of ASTM Standards. Vol. 03.02, 1989.

(15) ASTM G61-86. Standard Test Method for Conducting Cyclic Potentiodynamic Polarization Measurements for 
Localized Corrosion Susceptibility of Iron-, Nickel-, or Cobalt-Based Alloys. Annual Book of ASTM Standards. Vol. 03.02, 1989.

(16) Soria, L. y Herrera, J. Medida de la tendencia a la corrosión por picaduras de los aceros inoxidables austeníticos por métodos potenciodinámicos. Congreso Nacional de Ciencia y Tecnología Metalúrgicas. Madrid, Oct. 1990.

(17) Qvarfort, R. Corros. Sci., 28 (2), 1988: 135-140.

(18) Olfield, J.W. y Kain, R.M. Prediction of Crevice Corrosion Resistance of Stainless Steels in Aqueous Environments - A Corrosion Engineering Guide. $12^{\circ}$ Congreso
Intenacional de Corrosión NACE. Houston, Texas (EE.UU.), Sep., 1993.

(19) Qvarfort, R. y Alfonsson, E. Pitting Corrosion Testing with an Improved Method. Congreso Europeo de la Corrosión. Utrecht (Países Bajos), Sep. 1989.

(20) Gonzalez, J.A. Control de la Corrosión: estudio y medida por técnicas electroquímicas. CENIM (CSIC) Madrid. 1989: 376-378.

(21) Patel, C. Potentiodynamic testing and significance in investigating localized corrosion failures in oldfield systems. Corrosion: Industrial Problems, Treatment and Control Techniques. Ed. Pergamon Press. 1987: 173-194. 